\section{Ultraviolet Fluorescence to Identify Navel Oranges with Poor Peel Quality and Decay}

\author{
David Obenland $^{1,3}$, Dennis Margosan ${ }^{1}$, Joseph L. Smilanick ${ }^{1}$, \\ and Bruce Mackey ${ }^{2}$
}

\begin{abstract}
ADDITIONAL INDEX WORDs. Citrus sinensis, black light, sorting
SUMMARY. Navel oranges (Citrus sinensis) were sorted into four groups under ultraviolet illumination in commercial packinghouse black light rooms based upon the amount of fluorescence visible on each fruit to determine if fluorescence was predictive of peel quality. The groups corresponded to fruit with 1) little or no fluorescence (group 0), 2) low fluorescence (group 1), 3) moderate fluorescence (group 2), and 4) large fluorescent areas (group 3) that were indicative of developing decay lesions. Identification and elimination of group 3 fruit in black light rooms is a common practice now, but the other groups pass through these rooms. Six tests were conducted over a 2 -year period during different times in the mid to late navel orange season. Fruit were visually evaluated for peel quality within 24 hours of their initial segregation into fluorescence groups and again following 3 weeks of storage at $15^{\circ} \mathrm{C}$. Peel quality assessment was based upon commercial grading practices, and the fruit were placed into fancy, choice, juice, or decay classes. Fruit with low to no peel fluorescence (groups 0 and 1 ) had numerous fancy-grade fruit and few juice- and decay-grade fruit in comparison with the other two groups. In contrast, fruit with moderate fluorescence (group 2) were of poor peel quality. In the initial evaluation, this group had $28 \%$ fewer fancy fruit and $19 \%$ more juice fruit than did group 0 . During storage, group 2 fruit declined markedly in quality and numerous fruit of group 2 in the choice and juice classes decayed; the percentage of decayed fruit increased from $1 \%$ initially to $29 \%$ after 3 weeks of storage. Navel oranges in group 3, with numerous and obvious fluorescent decay lesions, mainly consisted of either juice grade or decayed fruit; $70 \%$ of group 3 decayed after 3 weeks. In addition to removing fluorescing fruit that have obvious indications of decay (group 3), it would be advantageous to remove or otherwise recognize that fruit with moderate levels of fluorescence (group 2) are also of lower quality and that they should not be selected for long storage or distant transport. Their identification may be most practical with an automated system using machine vision and ultraviolet illumination.
\end{abstract}

A common practice in orange (Citrus sinensis) packinghouses worldwide is to pass fruit on the packing line through a darkened room equipped with ultraviolet lights (black light room) as an initial step in the packing process. This procedure takes advantage of the fact that incipient decay lesions caused by the green mold or blue mold pathogens (Penicillium digitatum or Penicillium italicum, respectively), and other severely damaged areas on the fruit display a bright yellow fluorescence in the affected areas, allowing workers to easily cull

This work was partially-funded by a grant from the Citrus Research Board.

We thank Paul Neipp for his assistance in conducting this project.

${ }^{1}$ San Joaquin Valley Agricultural Sciences Center, USDA ARS, Parlier, CA 93648

${ }^{2}$ Western Regional Research Center, USDA ARS, Albany, CA 94710

${ }^{3}$ Corresponding author. E-mail: david.obenland@usda. ars.gov. these fruit. Elimination of these fruit early in the packing process not only improves the overall quality of the fruit lot but also limits the spread of these pathogens through the rest of the packing line.

The peel of navel oranges and other citrus (Citrus spp.) contain large amounts of essential oils that reside both within (Bosabalidis and Tsekos, 1982; Shomer, 1980) and outside (Obenland et al., 1997) of the oil glands in the flavedo. Tangeretin, a polymethoxylated flavone that is a component of the peel oil (Swift, 1967), fluoresces under ultraviolet light and is a likely source of the yellow fluorescence visible from damaged or decayed oranges in the black light rooms. During decay, the peel breaks down and allows the oil components to migrate closer to the peel surface, becoming visible with ultraviolet illumination. Other damage, such as punctures or large cracks in the peel, directly liberates the oil and causes the areas there to be highly visible under ultraviolet illumination. Peel oil also may be more than an indicator of rind injury as in many instances it is known to be phytotoxic and may be involved in causing or at least exacerbating the peel injury (Brodrick, 1970; Fawcett, 1916; Obenland et al., 1997).

Upon observing numerous lots of fruit in a packinghouse black light room, it is immediately obvious that there are many oranges that fluoresce under ultraviolet illumination which are not removed by packinghouse workers because the areas of fluorescence do not have the characteristic appearance of decay lesions, which typically have large, circular, brightly fluorescing areas. Anecdotal reports from a number of packinghouse managers in California indicate that orange lots with high levels of fluorescence are inferior in quality and decline in quality more rapidly during storage, yet no research has been done to substantiate this. Some recent researchers examined the use of ultraviolet-induced fluorescence as a portion of a multispectral analysis system to identify and classify peel defects in citrus (Blasco et al., 2007, 2009); however, the work used fruit with a limited number of known peel problems using machine vision in the laboratory and was targeted toward being able to differentiate between various peel imperfections. The objective of this project was to evaluate under commercial packinghouse conditions, using multiple fruit lots and during different portions of the harvest season, the ability of ultraviolet-induced fluorescence to categorize the peel quality of navel oranges based upon commercially accepted grade standards.

\begin{tabular}{llll}
\hline $\begin{array}{l}\text { Units } \\
\begin{array}{l}\text { To convert U.S. to SI, } \\
\text { multiply by }\end{array}\end{array}$ & U.S. unit & SI unit & $\begin{array}{l}\text { To convert SI to U.S., } \\
\text { multiply by }\end{array}$ \\
\hline 0.3048 & $\mathrm{ft}$ & $\mathrm{m}$ & 3.2808 \\
25.4 & inch $(\mathrm{es})$ & $\mathrm{mm}$ & 0.0394 \\
$\left({ }^{\circ} \mathrm{F}-32\right) \div 1.8$ & ${ }^{\circ} \mathrm{F}$ & ${ }^{\circ} \mathrm{C}$ & $\left(1.8 \times{ }^{\circ} \mathrm{C}\right)+32$ \\
$\left({ }^{\circ} \mathrm{F} \div 1.8\right)+255.37$ & ${ }^{\circ} \mathrm{F}$ & $\mathrm{K}$ & $(\mathrm{K}-255.37) \times 1.8$
\end{tabular}




\section{Materials and methods}

Navel oranges were rated for peel fluorescence while the fruit were under ultraviolet light on a running line in a packinghouse black light room and placed into one of four different groups based upon the amount of fluorescence observed (Fig. 1). Illumination was from 40-W, 4-ft-long tubular ultraviolet-A fluorescent lamps, placed $\approx 0.5 \mathrm{~m}$ above a roller bed, where the fruit rotated $\approx 60$ times per minute. The amount of fluorescence that characterized each group was as follows: group 0 , little or no fluorescence; group 1, a small number (10 or less) of discrete yellow spots, generally $3 \mathrm{~mm}$ or less in diameter; group 2, greater than 10 yellow spots, the diameters of most spots exceeding $3 \mathrm{~mm}$ in diameter; group 3, one or more large (generally larger than $10 \mathrm{~mm}$ diameter), circular, brightly fluorescing yellow lesions. Fruit classified in group 3 were those that are currently removed from the line by workers in the packinghouse black light rooms. It is recognized that the group classifications varied somewhat by fruit lot because of the differences in the overall abundance of fluorescence present, but that the groups approximated the descriptions given.

Navel oranges were taken from two packinghouses in the California San Joaquin Valley. The first three tests were conducted in Apr., May, and June 2008 in packinghouse 1. These harvests were relatively late in the navel season, and these fruit are known to have less storage potential than those harvested earlier in the season. The final three tests were conducted in Dec. 2009, Feb. 2010, and Apr. 2010 in packinghouse 2. The December and February harvests were midseason and these fruit

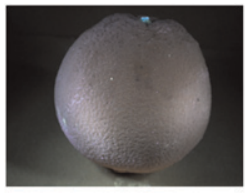

0

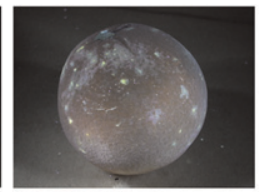

1

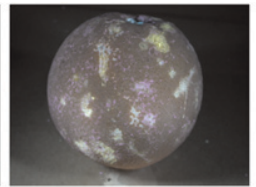

2

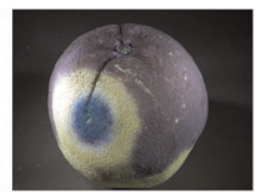

3
Group

Fig. 1. Navel oranges under ultraviolet illumination showing the average appearance of each of the four fluorescence groups. Groups were selected under ultraviolet and categorized for degree of fluorescence while the fruit were on the packing line before storage. Under current packinghouse practices, only fruit from group 3 would be removed from the packing line. response as a binomial, with test being considered as a random effect. The significance of evaluation date was determined by specifying in SAS a group $\times$ class slice of the evaluation $\times$ group $\times$ class interaction. Contrast statements among the interaction least-squares means were used to estimate the significance of differences between groups within each quality class, using the Bonferroni adjustment to control for the number of comparisons made.

\section{Results and discussion}

Numerous fruit were visible in each of the six tests, which had areas that fluoresced under ultraviolet illumination in the black light rooms, although the overall amount of fluorescence present differed greatly among the lots. The great majority of fruit had at least a small area of fluorescence. Some of the fluorescence patterns that were observed are shown in Figure 2 and are examples of large spots with well-defined areas (Fig. 2A and B), streaks apparently caused by peel oil running down the sides of the fruit (Fig. 2C and D), and fluorescing areas that appear to be above cuts in the peel (Fig. 2E and F). Although these fruit (categorized into fluorescence group 2) have strong fluorescence, they would not have been culled out in the black light room in the standard packing process as their fluorescence does not have the distinctive signature of decay. Fluorescence was still visible following 3 weeks of storage but was reduced in intensity in comparison with fruit evaluated within the first $24 \mathrm{~h}$ (data not shown).

The basis of some of the fluorescence was fairly evident as cuts or small wounds would be visible to the eye (Fig. 2E and F) and represented areas where the oil exited the peel or at least was very close to the surface and visible under ultraviolet light. In other instances, no wound could be readily seen while examining the fruit under visible light. Mechanical damage to the flavedo is sometimes known to result in the release of peel oil (Cahoon et al., 1963; Fawcett, 1916) and is a likely cause of much of the fluorescence observed in the black light room. Peel oil release occurs commonly with citrus, has long been cited as a cause of the peel disorder oleocellosis (Petracek et al., 2006), and is believed to be predominantly caused by postharvest damage to the 
peel induced by picking, transportation, and the packing process (Eaks, 1969; Smoot et al., 1971). In this study, it is unknown whether the fruit with enhanced amounts of fluorescence occurred as a result of postharvest handling, although packing did not influence peel condition since the black light rooms at both of the packinghouses were at the beginning of the line and the fruit we evaluated did not pass through to the packing process.

Variation was present in the proportion of fruit in each of the quality classes among the six tests (Fig. 3), one example being the higher percentages of fancy fruit being present in the first three tests. Although the tests, conducted at different times in the navel orange season and in two different packinghouses, had fruit with obvious differences in overall peel quality, the effect of sorting for fluorescing areas on the fruit was remarkably similar among the tests as can be seen by comparing the proportions of the various quality classes in each of the groups in Figure 3. A statistical analysis conducted across all the tests indicated that fluorescence groups strongly differed in the amount of each quality class present, as indicated by the significant group $\times$ class interaction in the analysis (Table 1 ). This was true even when group 3 , the most extreme group that contained fruit with large fluorescing lesions, was excluded from the analysis.

Fluorescence groups 0 and 1 were very similar in their peel quality across all tests, with both groups having relatively high percentages of fancy fruit and lower percentages of juice grade and decay fruit in comparison with the other two fluorescence groups (Fig. 4 ). Evidently, the low amounts of fluorescence in group 1 related to peel injuries of a severity that are not commercially important. Decay increased by $14 \%$ over the initial values (no decay present) in both groups because of storage and was the only quality class that was significantly impacted $(P<$ 0.0001 ) by storage in groups 0 and 1 . This increase in decay would likely have been less had the fruit been waxed and treated with a fungicide as is currently practiced in the citrus industry. The differences due to storage were not significant for the fancy, choice, or juice classes for these fluorescence groups.

Peel quality in group 2, on the other hand, was markedly worse than
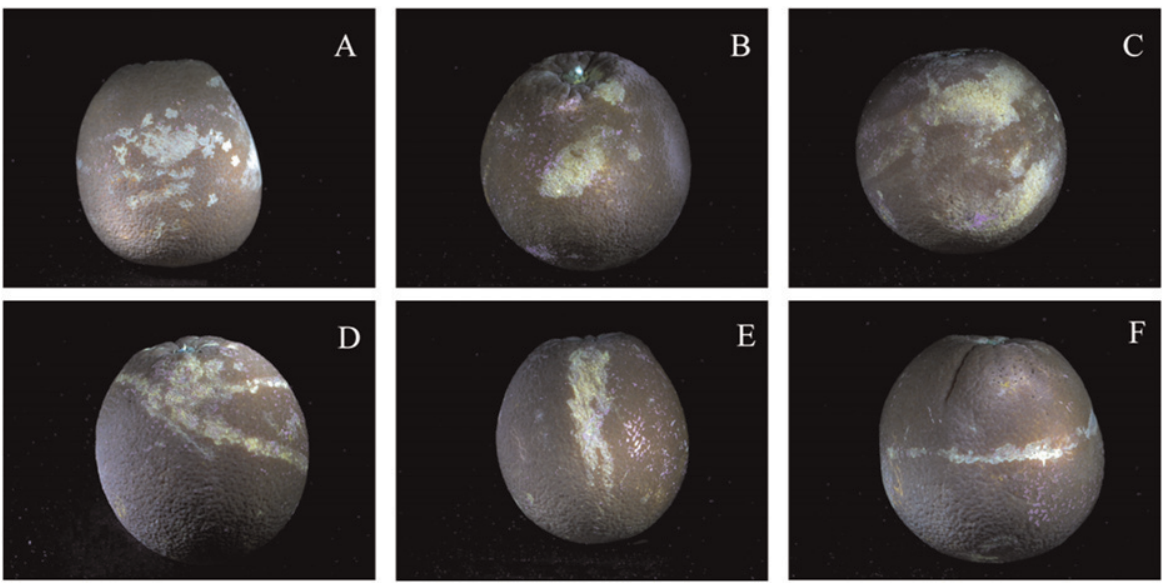

Fig. 2. Examples of oranges with large areas of fluorescence (shown under ultraviolet illumination) that normally are not culled from the packing line by packinghouse workers in the black light room. Shown are examples of large spots (A and B), streaks apparently caused by peel oil running down the sides of the fruit (C and D), and fluorescing areas above cuts in the peel (E and F).

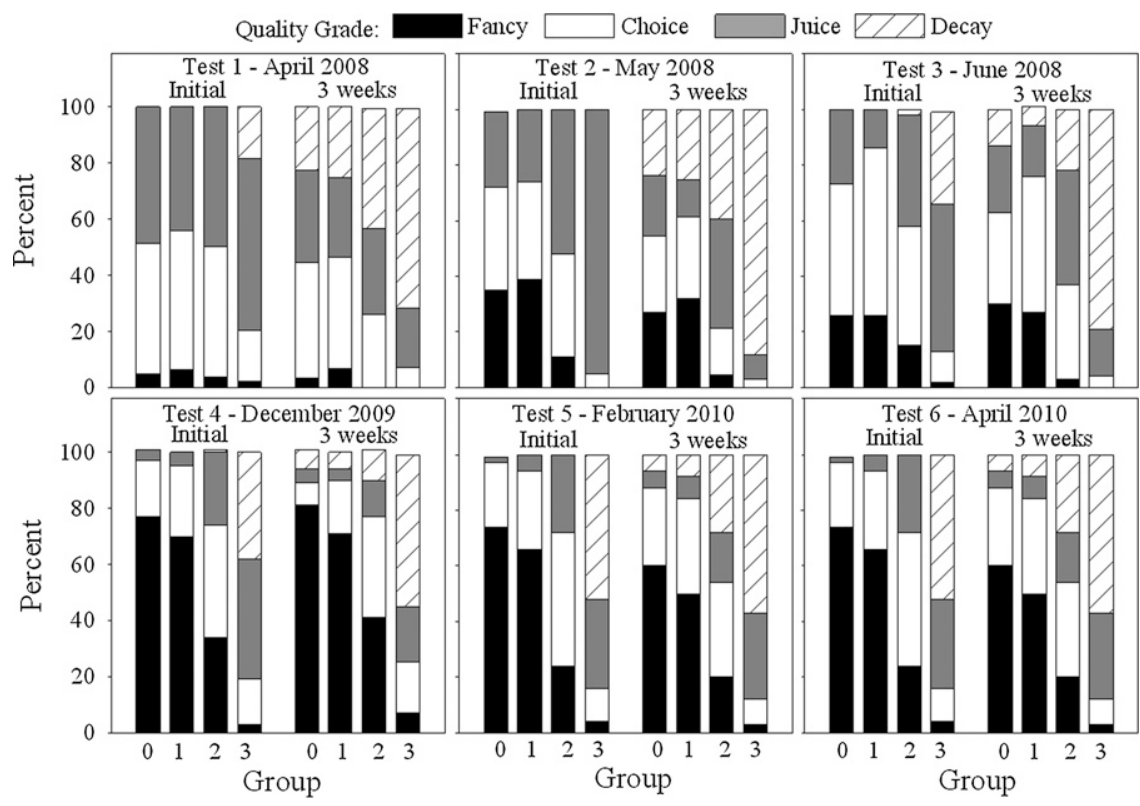

Fig. 3. Percentages of navel oranges in fancy, choice, juice, or decay quality classes (U.S. Department of Agriculture, 2010) that had been sorted into four fluorescence groups in packinghouse black light rooms under ultraviolet illumination.

Fluorescence groups corresponded to group 0 (little or no fluorescence), group 1 (low fluorescence), group 2 (moderate fluorescence), and group 3 (large fluorescent areas that were characteristic of decay). Grading of orange quality was done either within $24 \mathrm{~h}$ of sorting or following storage at $15{ }^{\circ} \mathrm{C}\left(59.0^{\circ} \mathrm{F}\right)$ for 3 weeks. Six different tests are presented.

that in groups 0 and 1 (Fig. 4). These differences were readily apparent in the initial evaluation where juice grade fruit made up a $20 \%$ greater proportion of the fruit, with correspondingly less fancy grade fruit. The proportion of fruit in the choice grade was similar among groups 0,1 , and 2 . The abundant fluorescence of the fruit peel that was noted in the black light room for group 2 appears to be directly related to blemishes on the peel that were commercially important. Storage induced a statistically significant change $(P \leq 0.05)$ in choice, juice, and decay fruit quality classes as choice and juice fruit decayed, increasing the percentage of the decayed fruit to $29 \%$. This indicates that in addition to being initially inferior at the time of 
Table 1. Statistical analysis for the effect of fluorescence group (G) and timing of evaluation $(\mathrm{E})$ on the proportion of navel oranges in each quality grade class $(\mathrm{C})$ including and excluding fluorescence group 3.

\begin{tabular}{lcccc}
\hline Effect & df & $\begin{array}{c}P>\text { F } \\
\text { (including group 3) }\end{array}$ & df & $\begin{array}{c}P>\text { F } \\
\text { (excluding group 3) }\end{array}$ \\
\hline Group $(\mathrm{G})$ & 3 & 0.8860 & 2 & 0.7197 \\
Evaluation (E) & 1 & 0.0006 & 1 & $<0.0001$ \\
G $\times$ E & 3 & 0.1292 & 2 & 0.8716 \\
Class $(C)$ & 3 & 0.0004 & 3 & $<0.0010$ \\
G $\times$ C & 9 & $<0.0001$ & 6 & 0.0058 \\
E $\times$ C & 3 & $<0.0001$ & 3 & $<0.0001$ \\
G $\times$ E $\times$ C & 9 & 0.0156 & 6 & 0.5148 \\
\hline
\end{tabular}

Fruit were rated under ultraviolet light and grouped based upon the degree of fluorescence present before storage, with group 3 having large fluorescent areas that were characteristic of decay. Class indicated the commercial grading class that the fruit corresponded to before and after storage.

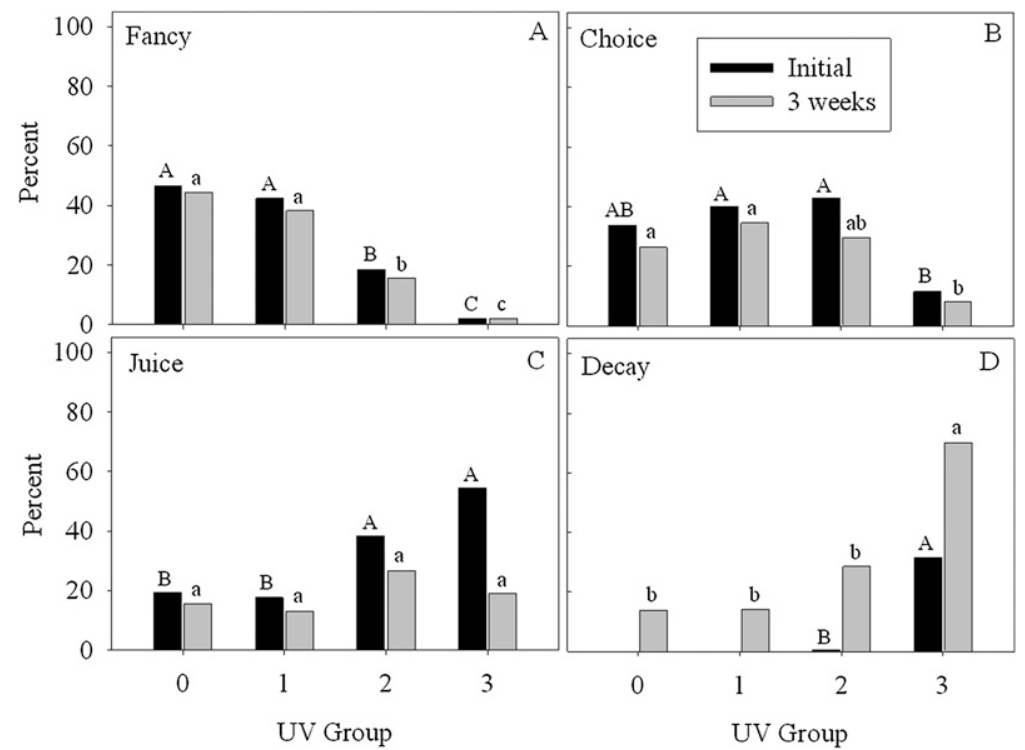

Fig. 4. Mean values across all six tests of percentages of navel oranges that had been classified into fancy, choice, juice, or decay quality classes (U.S. Department of Agriculture, 2010) following the grouping of the fruit into fluorescence groups based upon the peel fluorescence present under ultraviolet light. Grading of the fruit into peel quality classes occurred either within $24 \mathrm{~h}$ (initial) or following 3 weeks of storage at $15{ }^{\circ} \mathrm{C}\left(59.0{ }^{\circ} \mathrm{F}\right)$. Fluorescence groups corresponded to group 0 (little or no fluorescence), group 1 (low fluorescence), group 2 (moderate fluorescence), and group 3 (large fluorescent areas that were characteristic of decay). Different letters indicate statistical significance $(P \geq 0.05)$ among the four fluorescence groups within an evaluation time, using the Bonferroni method to adjust for the number of comparisons used.

packing, group 2 fruit also had poorer storability than groups 0 and 1 . In a commercial situation, where the fruit would have been treated with a fungicide, this decay rate would likely have been somewhat lower.

Fluorescence group 3 represented fruit that had large fluorescing lesions characteristic of decay that would normally be culled off the line in the black light room by packinghouse workers. As would be expected, this group had relatively few fancyand choice fruit as compared with the other three groups and had large numbers of decays or fruit destined for juice (Fig. 4). Initially, nearly a third $(32 \%)$ of the fruit were already decayed, while $55 \%$ were juice grade. During 3 weeks of storage, the percentages of juice grade and decay fruit were significantly altered $(P<0.0001)$ from the initial percentages as the juice-class fruit decayed. An average of $70 \%$ of the group 3 fruit decayed following storage, highlighting the usefulness of the current practice of removing these fruit before they become packed or contaminate the rest of the packing line with decay microorganisms.

The practical utility of this study for a packinghouse manager is that we have established that fruit lots with very low peel fluorescence are the highest in initial peel quality and are also those most likely to retain their quality during prolonged transport or extended storage, or to satisfy the needs of particularly fastidious buyers. Conceivably, the selection of fruit with minimal peel fluorescence could also be an important aspect of quality sought by fruit buyers, since these fruit will have the potential for longer shipping, storage, and display life. Furthermore, peel fluorescence can also be indicative of fruit that have experienced a significant freezing event, although the relationship of fluorescence to internal flesh damage may vary with the intensity of the freeze (Obenland et al., 2009).

It should be noted that we did not determine the actual commercial benefit of sorting for ultraviolet fluorescence in this study as it was not feasible to sort entire multibin fruit lots in the manner in which we performed our sampling. We recognize that further grading of the oranges normally occurs both electronically and manually following the black light room that could potentially remove at least some of the same fruit as the ultraviolet sorting that we were performing. Further experimentation is needed to fully define the potential effectiveness of ultraviolet sorting in comparison and in concert with current commercial fruit-sorting practices.

Sorting using ultraviolet illumination was performed by hand for this study, although it remains to be determined whether it would be possible to train workers to effectively remove group 2 fruit as these fruit would not be as easy to identify as are the group 3 fruit that are currently removed by these workers. Also, the speed of the packing line makes it difficult to effectively judge the degree of fluorescence present on each fruit. Using machine vision and mechanical sorting would be a logical means to perform this task, and research has been done to examine implementing ultraviolet as part of a citrus multispectral sorting system (Blasco et al., 2007, 2009). The feasibility of doing this with fruit with fluorescence signatures, such as group 
2 fruit in this study, needs to be determined.

\section{Literature cited}

Blasco, J., N. Aleixos, J. Gómez, and E. Moltó. 2007. Citrus sorting by identification of the most common defects using multispectral computer vision. J. Food Eng. 83:384-393.

Blasco, J., N. Aleixos, J. Gómez-Sanchís, and E. Moltó. 2009. Recognition and classification of external skin damage in citrus fruits using multispectral data and morphological features. Biosystems Eng. 103:137-145

Bosabalidis, A. and I. Tsekos. 1982. Ultrastructural studies on the secretory cavities of Citrus deliciosa Ten. II. Development of the essential oil-accumulating central space of the gland and process of active secretion. Protoplasma 112:63-70.

Brodrick, H.T. 1970. Investigations into blemishes on citrus fruits. III. The development of early and late injuries in relation to rind oils. South African Citrus J. 441:19-25.

Cahoon, G.A., B.L. Grover, and I.L. Eaks. 1963. Cause and control of oleocellosis on lemons. Proc. Amer. Soc. Hort. Sci. 84:188-198.

Eaks, I.L. 1969. Rind disorders of oranges and lemons in California. Proc. First Intl. Citrus Symp. 3:1343-1354.

Fawcett, H.S. 1916. A spotting of citrus fruits due to the action of oil liberated from the rind. California Agr. Expt. Sta. Bul. 266:259-270.

Obenland, D., D. Margosan, S. Collin, J. Sievert, K. Fjeld, M.L. Arpaia, J. Thompson, and D. Slaughter. 2009. Peel fluorescence as a means to identify freeze-damaged navel oranges. HortTechnology 19:379384 .

Obenland, D.M., D.A. Margosan, L.G. Houck, and L.H. Aung. 1997. Essential oils and chilling injury in lemon. HortScience 32:108-111.
Petracek, P.D., D.F. Kelsey, and W. Grierson. 2006. Physiological peel disorders, p. 397-419. In: W.F. Wardowski, W.M. Miller, D.J. Hall, and W. Grierson (eds.). Fresh citrus fruits. Florida Science Source, Longboat Key, FL.

Shomer, I. 1980. Sites of production and accumulation of essential oils in citrus fruits. Proc. Seventh European Congr. Electron Microsc. 2:256-257.

Smoot, J.J., L.G. Houck, and H.B. Johnson. 1971. Market diseases of citrus and other subtropical fruits. U.S. Dept. Agr. Hdbk. 398.

Swift, L.J. 1967. TLC-spectrophotometric analysis for neutral fraction flavones in orange peel juice. J. Agr. Food Chem. 15:99-101.

U.S. Department of Agriculture. 2010. United States Standards for Grades of Oranges (California and Arizona). 29 Oct. 2010. <http://www.ams.usda.gov/ AMSv1.0/getfile?dDocName=STELPRD C5050380>. 